Research, Society and Development, v. 10, n. 14, e515101420437, 2021

(CC BY 4.0) | ISSN 2525-3409 | DOI: http://dx.doi.org/10.33448/rsd-v10i14.20437

\title{
Soluções nutritivas salinizadas com cloreto de sódio no cultivo da alface crespa em sistema hidropônico
}

Nutritive solutions salinized with sodium chloride in the cultivation of crisp lettuce in a hydroponic system

Soluciones nutritivas salinizadas com cloruro de sódio en el cultivo de lechuga crujiente en sistema hidropónico

Recebido: 09/09/2021 | Revisado: 18/09/2021 | Aceito: 08/11/2021 | Publicado: 13/11/2021

Josilda de França Xavier ORCID: https://orcid.org/0000-0003-2624-4989 Universidade Federal de Campina Grande, Brasil E-mail: josildaxavier@yahoo.com.br

Carlos Alberto Vieira de Azevedo ORCID: https://orcid.org/0000-0001-7336-1243 Universidade Federal de Campina Grande, Brasil E-mail: cazevedo@deag.ufcg.edu.br

Márcia Rejane de Q. Almeida Azevedo ORCID: https://orcid.org/0000-0002-4391-2961 Universidade Estadual da Paraíba, Brasil E-mail: mazevedo@ccaa.uepb.edu.br

Julio Cesar Rodrigues de Sales ORCID: https://orcid.org/0000-0003-0855-019X Universidade Federal de Campina Grande, Brasil E-mail: julioo5rodrigues@outlook.com

Nattan Cardoso de Oliveira ORCID: https://orcid.org/0000-0003-3081-9685 Universidade Estadual da Paraíba, Brasil E-mail: 55nattan44@gmail.com Josely Dantas Fernandes ORCID: https://orcid.org/0000-0002-5563-6327 Universidade Estadual da Paraíba, Brasil E-mail: joselysolo@yahoo.com.br

\section{Resumo}

A pesquisa teve como objetivo a avaliar a produção das três cultivares da alface crespa (Elba, Cristina e Veneranda) cultivadas em sistema hidropônico-NFT utilizando soluções nutritivas salinizadas com cloreto de sódio. O experimento foi conduzido em ambiente protegido, no Centro de Ciências Agrárias e Ambientais-CCAA da Universidade Estadual da Paraíba-UEPB Campus-II, localizado na zona rural do município de Lagoa Seca-PB, com coordenadas geográficas: $\left(7^{\circ} 10^{\prime} 15^{\prime \prime} \mathrm{S}, 35^{\circ} 51^{\prime} 14^{\prime \prime} \mathrm{W}\right)$. O delineamento foi em blocos casualizados, em esquema de parcelas subdivididas, sendo as parcelas constituídas por soluções nutritivas com diferentes valores de condutividade elétrica $\left(\mathrm{S}_{2}-2,4 ; \mathrm{S}_{3}-2,9 ; \mathrm{S}_{4}-3,4 ; \mathrm{S}_{5}-3,9 ; \mathrm{S}_{6}-4,4\right.$ e $\left.\mathrm{S}_{7}-4,9 \mathrm{dS} \mathrm{m}{ }^{-1}\right)$ e as subparcelas por diferentes cultivares de alface crespa (Elba, Cristina e Veneranda), com três repetições. As variáveis analisadas foram: Número de folhas por planta-NFP; Produção Total-PT; Produção Comercial-PC; Diâmetro do Caule-DC; Massa Fresca da Folha-MFF, Massa Seca da Folha-MSF e Massa Seca do Caule-MSC. Independentemente da variável analisada, não houve interação significativa entre as soluções nutritivas e as cultivares. Em relação ao efeito isolado da solução, o maior número de folhas por planta, produção total e comercial e massa fresca de folhas foi obtido com o uso da solução $\mathrm{S}_{1}$. Quanto às cultivares, Veneranda apresentou a maior produção comercial, massa fresca e seca da folha e seca do caule, esta cultivar também apresentou a maior média, mas sem diferir da Elba, quando avaliados o número de folhas e a produção total.

Palavras-chave: Hidroponia; Lactuca sativa L.; Salinidade; Produtividade.

\section{Abstract}

The objective of this research was to evaluate the agronomic performance of three crispy lettuce cultivars (Elba, Cristina and Veneranda) grown in a hydroponic-NFT system using nutrient solutions salinized with sodium chloride. The experiment was conducted in a protected environment, at the Center for Agricultural and Environmental Sciences-CCAA of the State University of Paraíba-UEPB Campus-II, located in the rural area of the city of Lagoa 
Research, Society and Development, v. 10, n. 14, e515101420437, 2021

(CC BY 4.0) | ISSN 2525-3409 | DOI: http://dx.doi.org/10.33448/rsd-v10i14.20437

Seca-PB, with geographical coordinates: $\left(7^{\circ} 10^{\prime} 15^{\prime \prime} \mathrm{S}, 35^{\circ} 51^{\prime} 14^{\prime \prime} \mathrm{W}\right)$. The design was in randomized blocks, in a split-plot scheme, the plots consisted of nutrient solutions with different values of electrical conductivity $\left(\mathrm{S}_{2}-2.4 ; \mathrm{S}_{3}-\right.$ 2.9; $\mathrm{S}_{4}-3.4 ; \mathrm{S}_{5}-3.9 ; \mathrm{S}_{6}-4.4$ and $\mathrm{S}_{7}-4.9 \mathrm{dS} \mathrm{m}^{-1}$ ) and the subplots by different cultivars of curly lettuce (Elba, Cristina and Veneranda), with three replications. The variables evaluated were: Number of leaves per plant-NFP; Total productionPT; Commercial production-PC; Stem diameter-DC; Fresh leaf mass-MFF Dry leaf mass-MSF and Dry stem massMSC. Regardless of the variable analyzed, there was no significant interaction between nutrient and cultivar solutions. Regarding the isolated effect of the solution, the largest number of leaves per plant, total and commercial production and fresh leaf mass was obtained with the use of the $S_{1}$ solution. As for the cultivars, Veneranda presented the highest commercial production, fresh and dry mass of the leaf and dry of the stem, this cultivar also presented the highest average, but without differing from the Elba, when the number of leaves and total production was evaluated.

Keywords: Hydroponics; Lactuca sativa L.; Salinity; Productivity.

\section{Resumen}

El objetivo de esta investigación fue evaluar el desempeño agronómico de tres cultivares de lechuga crujiente (Elba, Cristina y Veneranda) cultivados en un sistema hidropónico-NFT utilizando soluciones nutritivas salinizadas con cloruro de sodio. El experimento se realizó en un ambiente protegido, en el Centro de Ciencias Agrícolas y Ambientales-CCAA de la Universidad Estatal de Paraíba-UEPB Campus-II, ubicado en la zona rural del municipio de Lagoa Seca-PB, con coordenadas geográficas: $\left(7^{\circ} 10^{\prime} 15^{\prime \prime} \mathrm{S}, 35^{\circ} 51^{\prime} 14^{\prime \prime} \mathrm{W}\right)$. El diseño fue en bloques al azar, en un esquema de parcelas divididas, con las parcelas constituidas por soluciones nutritivas con diferentes valores de conductividad eléctrica (S2-2.4; S3-2.9; S4-3.4; S5-3.9; S6-4.4 y S7-4.9 dS m-1) y las subparcelas por diferentes cultivares de lechuga crujiente (Elba, Cristina y Veneranda), con tres repeticiones. Las variables analizadas fueron: Número de hojas por planta-PFN; Producción total-PT; PC de producción comercial; Diámetro del vástago-DC; Masa de hoja fresca-MFF, Masa seca de hoja-MSF y Masa seca de tallo-MSC. Independientemente de la variable analizada, no hubo interacción significativa entre las soluciones nutritivas y los cultivares. En cuanto al efecto aislado de la solución, el mayor número de hojas por planta, producción total y comercial y masa fresca de hojas se obtuvo utilizando la solución S1. En cuanto a los cultivares, Veneranda tuvo la mayor producción comercial, masa fresca y seca de hojas y masa seca de tallo, este cultivar también tuvo el promedio más alto, pero sin diferenciarse de Elba, cuando se evaluó el número de hojas y la producción total.

Palabras clave: Hidroponía; Lactuca sativa L.; Salinidade; Productividad.

\section{Introdução}

A salinidade elevada pode causar distúrbios nutricionais, especialmente em plantas sensíveis. De acordo com López et al. (2014), as concentrações dos íons $\mathrm{Na}+\mathrm{e} \mathrm{Cl}$ - podem ultrapassar as concentrações de outros nutrientes essenciais e resultar em distúrbios para a absorção de $\mathrm{Ca}_{2}+\mathrm{e} \mathrm{K}+$, modificando a absorção radicular desses nutrientes e sua translocação na planta.

A absorção de nutrientes pode ser comprometida em situações em que as plantas estejam submetidas ao estresse salino, ocasionado, principalmente, pelo acúmulo de sódio no tecido foliar, sendo o cálcio um dos componentes mais afetados (Paulus; Dourado Neto; Paulus, 2012). O excesso de sódio e cloro na água provoca a redução na absorção de potássio, cálcio e magnésio (Soares et al., 2016; Cova et al., 2017). O cálcio tem muitos efeitos sobre o crescimento e desenvolvimento da planta (Taiz et al., 2017).

A alta salinidade da solução nutritiva, o crescimento, a expansão da superfície foliar e o metabolismo do carbono primário de muitas culturas são afetados negativamente devido ao efeito osmótico, déficit hídrico, toxicidade de íons e desequilíbrio nutricional (De Pascale et al., 2013). Entretanto, quando se dispõe apenas de água salina, a condutividade elétrica da água da solução nutritiva deve ser considerada como o principal fator de restrição da produção (Kim et al., 2016), uma vez que seus efeitos de toxicidade e osmótico são mais severos do que os causados pelo excesso de fertilizantes utilizados na composição da solução nutritiva.

A solução nutritiva para o cultivo hidropônico é de fundamental importância, pois o crescimento e desenvolvimento da cultura dependerão de uma formulação adequada (Oliveira et al., 2014). A qualidade da água utilizada no preparo da solução nutritiva é fator fundamental para se obter elevada produtividade e qualidade dos produtos, seja no cultivo utilizando o sistema NFT (Paulus et al., 2011). Silva et al. (2015) estudaram quatro níveis de condutividade elétrica da água (CE): 0,43 (testemunha); 3,09; 6,87 e 8,53 $\mathrm{dS} \mathrm{m}^{-1}$. 
Research, Society and Development, v. 10, n. 14, e515101420437, 2021

(CC BY 4.0) | ISSN 2525-3409 | DOI: http://dx.doi.org/10.33448/rsd-v10i14.20437

O uso da hidroponia surgiu como uma alternativa a problemas como a baixa disponibilidade de solos aptos à agricultura; a incidência de determinadas doenças de solo, dificilmente controladas por métodos químicos, sanitários ou de resistência genética; o interesse em incrementar a eficiência do uso da água e o desejo de aumentar a produção e melhorar a qualidade dos alimentos (Souza Neta et al., 2013).

O cultivo de alface (Lactuca sativa L.) se destaca no cenário nacional de cultivos em hidroponia, sendo responsável por aproximadamente $80 \%$ da produção agrícola brasileira desse sistema (Alves et al., 2011). Vários estudos já foram realizados com o cultivo da alface usando a técnica de hidroponia, Paulus et al. (2012) e Sarmento et al. (2014).

O objetivo desta pesquisa foi avaliar o desempenho agronômico de três cultivares da alface crespa (Elba, Cristina e Veneranda) cultivadas em sistema hidropônico-NFT utilizando soluções nutritivas salinizadas com cloreto de sódio.

\section{Metodologia}

O experimento foi conduzido em ambiente protegido (casa de vegetação) do Centro de Ciências Agrárias e AmbientaisCCAA da Universidade Estadual da Paraíba-UEPB, situado na zona rural da cidade de Lagoa Seca-PB, com as seguintes coordenadas geográficas: $\left(7^{\circ} 10^{\prime} 15^{\prime \prime} \mathrm{S}, 35^{\circ} 51^{\prime} 14^{\prime \prime} \mathrm{W}\right)$, segundo a classificação climática de Köppen-Geige (Brasil, 1971) o clima do município é caracterizado como tropical úmido, com temperatura média anual em torno de $22^{\circ} \mathrm{C}$, sendo a mínima de $18^{\circ} \mathrm{C}$ e a máxima de $33^{\circ} \mathrm{C}$, no período de novembro a dezembro de 2019 . O sistema hidropônico utilizado foi o Fluxo Laminar de Nutrientes-NFT. Durante a condução do experimento, registraram-se diariamente os valores da temperatura máxima, mínima, média. As temperaturas foram registradas as 8h00, cujos dados estão demonstrados na (Figura 1).

Figura 1. Dados de temperaturas máxima, mínima e média e registradas as 8:00h durante a condução do experimento.

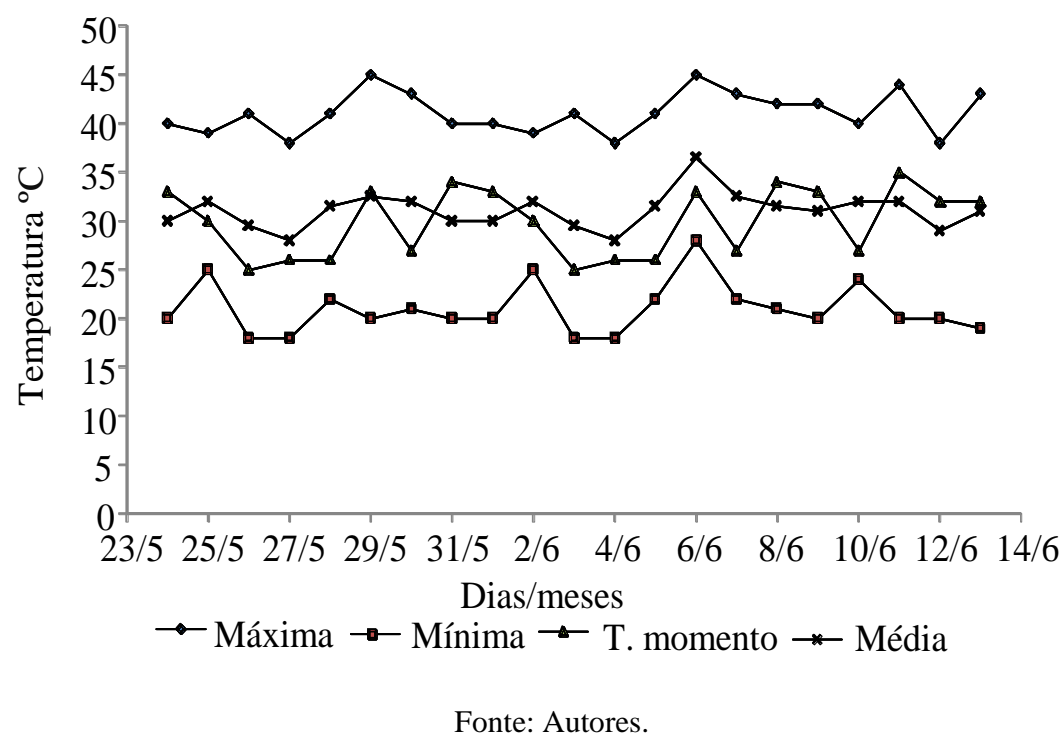

O delineamento do experimento foi em blocos casualizados, em esquema de parcelas subdivididas, sendo as parcelas constituídas por sete soluções nutritivas todas preparadas a partir da metodologia de Furlani (1995) de modo que a solução $S_{1}$ apresentou uma CE de $1,9 \mathrm{dS} \mathrm{m}{ }^{-1}$ e as soluções $S_{2}, S_{3}, S_{4}, S_{5}, S_{6}$ e $S_{7}$ os seguintes valores de CE: 2,4; 2,9; 3,4; 3,9; 4,4 e 4,9 dS $\mathrm{m}^{-1}$, respectivamente. As subparcelas corresponderam a três cultivares de alface crespa (Elba, Cristina e Veneranda), com 10 plantas/subparcela. Com exceção da solução $\mathrm{S}_{1}$, as demais soluções tiveram seus valores de $\mathrm{CE}$ aumentados pelo acréscimo do Cloreto de sódio $(\mathrm{NaCl})$. Todas as soluções nutritivas foram preparadas com água de chuva com $\mathrm{CE} 0,156 \mathrm{dS} \mathrm{m}^{-1} \mathrm{de}$ modo a se obter um volume de 200 litros (L) de solução estoque. 
Research, Society and Development, v. 10, n. 14, e515101420437, 2021

(CC BY 4.0) | ISSN 2525-3409 | DOI: http://dx.doi.org/10.33448/rsd-v10i14.20437

Os quantitativos dos fertilizantes minerais e da composição química da solução nutritiva mineral estão dispostos nas

Tabelas 1 e 2. Todas as soluções foram preparadas para $200 \mathrm{~L}$, conforme a metodologia proposta por Furlani et al. (1995).

Tabela 1. Quantitativos dos fertilizantes no preparo das soluções nutritivas minerais de estoques.

\begin{tabular}{|c|c|}
\hline \multicolumn{2}{|c|}{ Solução } \\
\hline Sais & \\
\hline \multicolumn{2}{|c|}{ g $1000 \mathrm{~L}^{-1}$ de água } \\
\hline $\mathrm{Ca}\left(\mathrm{NO}_{3}\right)_{2} ; 6 \mathrm{H}_{2} \mathrm{O}$ - Nitrato de cálcio & 1000 \\
\hline MAP - Fosfato monoamônio & 150 \\
\hline DAP - Fosfato diamônio & - \\
\hline $\mathrm{H}_{2} \mathrm{PO}_{4}$ - Ácido fosfórico & - \\
\hline $\mathrm{KH}_{2} \mathrm{PO}_{4}$ - Fosfato monopotássico & - \\
\hline $\mathrm{KCl}$ - Cloreto de potássio & 150 \\
\hline KNO3 - Nitrato de potássio & 600 \\
\hline $\mathrm{MgSO}_{4} .7 \mathrm{H}_{2} \mathrm{O}-$ Sulfato de magnésio & 250 \\
\hline MnCl. $\mathrm{H}_{2}$ - O Cloreto de manganês & 2,34 \\
\hline $\mathrm{Mn} \mathrm{SO}_{4} \cdot \mathrm{H}_{2} \mathrm{O}$ - Sulfato de manganês & - \\
\hline $\mathrm{ZnSO}_{4} .7 \mathrm{H}_{2} \mathrm{O}$ - Sulfato de zinco & 0,88 \\
\hline $\mathrm{CuSO}_{4} .7 \mathrm{H}_{2} \mathrm{O}$ - Sulfato de cobre & 0,2 \\
\hline $\mathrm{H}_{3} \mathrm{BO}_{3}$ - Ácido bórico & 2.04 \\
\hline $\mathrm{Na}_{2} \mathrm{MoO}_{4} \cdot 2 \mathrm{H}_{2} \mathrm{O}$ - Molibidato de amônio & 0,26 \\
\hline Fe-EDTA - Ferro EDTa. & $1000 \mathrm{~mL}$ \\
\hline
\end{tabular}

Fonte: Furlani (1995).

Tabela 2. Composição química das soluções nutritivas minerais.

\begin{tabular}{cc}
\hline \multicolumn{1}{c}{ Sais } & Solução \\
\hline g $1000 \mathrm{~L}^{-1}$ de água & Furlani \\
$\mathrm{NO}_{3}$ - Nitrato & 200,44 \\
$\mathrm{NH}_{4}$ - Amônio & 16,51432 \\
$\mathrm{P}-$ Fósforo & 32,7 \\
$\mathrm{~K}$ - Potássio & 310,275 \\
$\mathrm{Ca}-$ Cálcio & 168 \\
$\mathrm{Mg}$ - Magnésio & 24,65 \\
$\mathrm{~S}-$ Enxofre & 32,5 \\
$\mathrm{Mn}$ - Manganês & 0,636714 \\
Zn - Zinco & 0,199144 \\
Cu - Cobre & 0,0671 \\
Bo - Boro & 0,356592 \\
Mo - Molibdênio & 0,114452 \\
Fe- Ferro & 2,234 \\
\hline
\end{tabular}

Fonte: Furlani (1995). 
Research, Society and Development, v. 10, n. 14, e515101420437, 2021

(CC BY 4.0) | ISSN 2525-3409 | DOI: http://dx.doi.org/10.33448/rsd-v10i14.20437

A água utilizada para a formulação das soluções nutritivas foi proveniente da precipitação (chuva), armazenada em cisterna. A analise físico-química da água (Tabela 3) foi realizada no Laboratório de Irrigação e Salinidade da Unidade Acadêmica de Engenharia Agrícola da Universidade Federal de Campina Grande (LIS/UAEA/UFCG).

Tabela 3 - Caracterização físico-química da água utilizada nas irrigações do cultivo hidropônico.

\begin{tabular}{cc}
\hline Determinações & 8,09 \\
\hline pH & 0,156 \\
Condutividade Elétrica $\left(\mathrm{dS} . \mathrm{m}^{-1}\right)$ & 1,20 \\
Cálcio $\left(\mathrm{mmol}_{\mathrm{c}} / \mathrm{L}\right)$ & 0,15 \\
Magnésio $\left(\mathrm{mmol}_{\mathrm{c}} / \mathrm{L}\right)$ & 0,12 \\
Sódio $\left(\mathrm{mmol}_{\mathrm{c}} / \mathrm{L}\right)$ & 0,07 \\
Potássio $\left(\mathrm{mmol}_{\mathrm{c}} / \mathrm{L}\right)$ & 0,50 \\
Cloretos $\left(\mathrm{mmol}_{\mathrm{c}} / \mathrm{L}\right)$ & 0,20 \\
Carbonatos $\left(\mathrm{mmol}_{\mathrm{c}} / \mathrm{L}\right)$ & 0,90 \\
Bicarbonato $\left(\mathrm{mmol}_{\mathrm{c}} / \mathrm{L}\right)$ & Ausente \\
Sulfatos & 0,15 \\
Relação de adsorção de sódio $(\mathrm{RAS})$ & $\mathrm{C} 1$ \\
Classe de água para irrigação & \\
\hline
\end{tabular}

Fonte: Autores.

Durante a condução do experimento as leituras e as calibrações das soluções para potencial hidrogeniônico (pH) (Figura 2.A) e condutividade elétrica (CE) (Figura 2.B) foram realizadas em um intervalo de 24 horas, utilizando-se um condutivímetro portátil (TDS)/Temperatura modelo HI 9811-5. A CE foi mantida a aproximadamente $1,9 \pm 0,3 \mathrm{dS} \mathrm{cm}^{-1} \mathrm{e} \mathrm{o} \mathrm{pH}$ entre 5,5 e 6,5; independente dos tratamentos, as soluções nutritivas foram trocadas em períodos equidistantes de 7 dias. Após a calibração, o pH das soluções eram ajustadas mantendo-o próximo à neutralidade, com a utilização de uma solução de hidróxido de sódio $(\mathrm{NaOH})$ ou Ácido clorídrico (HCL), ácido sulfúrico $\mathrm{H}_{2} \mathrm{~S}_{\mathrm{O}} 4\left(1 \mathrm{~mol} \mathrm{~L} \mathrm{~L}^{-1}\right)$. A variação do pH foi feito considerando a média da concentração molar dos íons de hidrogênio $(\mathrm{H}+)$ utilizando a expressão pH $=-\log [\mathrm{H}+]$.

Figura 2. Variação do potencial hidrogeniônico (A), Condutividade elétrica (B) das três cultivares da alface crespa durante o período experimental das soluções nutritivas $S_{1}=100 \%$ da solução de Furlani (CE 1,9 dS m ${ }^{-1}$ ) e $S_{2} ; S_{3} ; S_{4} ; S_{5} ; S_{6}$ e $S_{7}$ adicionadas com cloreto de sódio $(\mathrm{NaCl})$ de modo a apresentarem as seguintes condutividades elétricas: 2,4;2,9; 3,4; 3,9; 4,4 e $4,9 \mathrm{dS} \mathrm{m}^{-1}$, respectivamente.

A

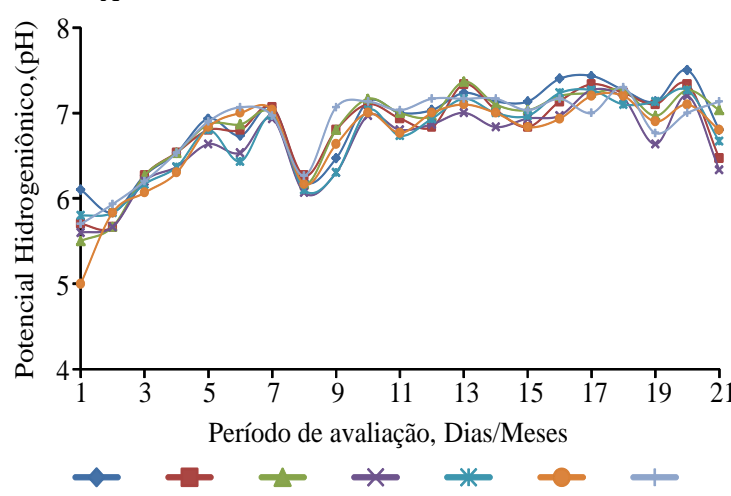

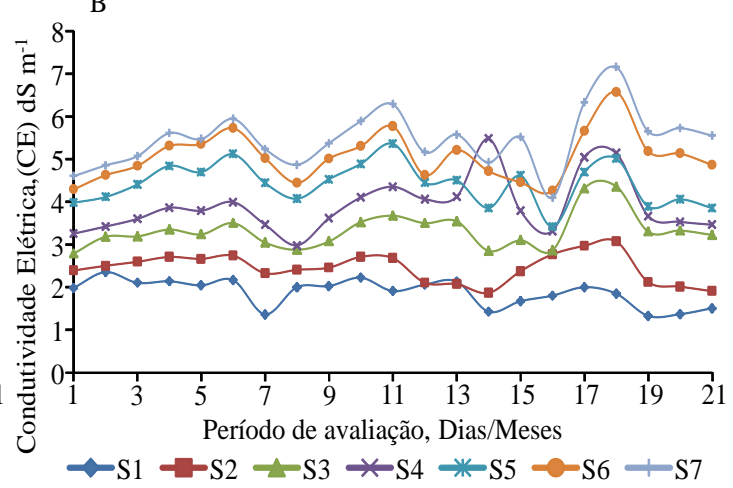

Fonte: Autores. 
A condutividade elétrica, em função dos tratamentos, foi ajustada quando observou-se uma variação de $20 \%$ para mais ou para menos da CE inicial, acrescentando água (da cisterna) ou solução estoque, respectivamente. Independente dos tratamentos, as soluções nutritivas foram trocadas em períodos equidistantes de sete dias.

O volume da solução que alimentava o sistema (NFT) durante o cultivo da alface foi acondicionado em baldes plásticos com capacidade para $20 \mathrm{~L}$, entretanto, para se evitar o desperdício de solução por transbordamento do balde, utilizou-se o volume de $17 \mathrm{~L}$. Com o intuito de se manter a solução nutritiva dentro dos limites de temperatura recomendados para o cultivo hidropônico, os baldes foram revestidos com folhas de Etileno Acetato de Vinila (E.V.A) com espessura de $5 \mathrm{~mm}$.

A quantificação do volume evapotranspirado pelas plantas (VETc), em função das soluções nutritivas, foi efetuada diariamente (Figura 3), completando o volume do reservatório até o nível de 17 litros, utilizando uma proveta graduada em mililitros conforme a Equação 1. A VETc foi considerada como uma variável quantitativa para estabelecer uma análise de regressão polinomial.

$$
\begin{aligned}
& \text { VETc }=\frac{V i}{\mathrm{n} \cdot \Delta \mathrm{t}} \\
& \mathrm{VETc}-\text { volume evapotranspirado, em } \mathrm{L} \text { planta }{ }^{-1} \mathrm{dia}^{-1} \\
& \mathrm{Vi}-\text { volume de solução consumida do intervalo de tempo de } 24 \mathrm{~h} 00 \\
& \Delta \mathrm{T}-\text { intervalo de tempo entre as leituras, dias; } \\
& \mathrm{n}-\text { numero de plantas no perfil no intervalo de tempo, } \Delta \mathrm{T} \text {. }
\end{aligned}
$$

Figura 3. Variação do consumo hídrico (C) das três cultivares da alface crespa durante o período experimental das soluções nutritivas $\mathrm{S}_{1}=100 \%$ da solução de Furlani $\left(\mathrm{CE} 1,9 \mathrm{dS} \mathrm{m}{ }^{-1}\right)$ e $\mathrm{S}_{2} ; \mathrm{S}_{3} ; \mathrm{S}_{4} ; \mathrm{S}_{5} ; \mathrm{S}_{6}$ e $\mathrm{S}_{7}$ adicionadas com cloreto de sódio (NaCl) de modo a apresentarem as seguintes condutividades elétricas: 2,$4 ; 2,9 ; 3,4 ; 3,9 ; 4,4$ e 4,9 dS m m $^{-1}$, respectivamente.

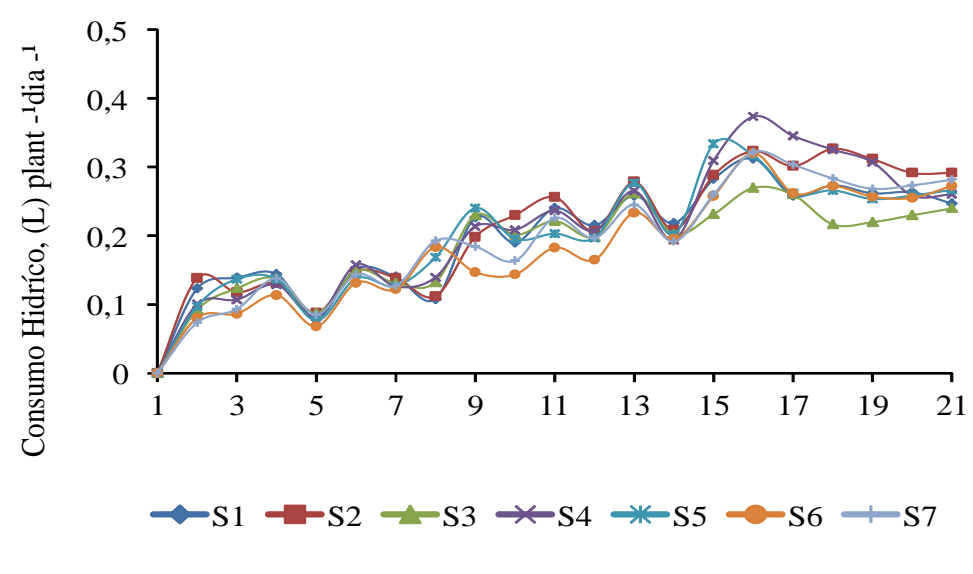

Fonte: Autores.

A Semeadura das sementes das três cultivares da alface crespa foi realizada em espuma fenólica (com três cm de diâmetro e dois cm de altura previamente) previamente enxaguada com água corrente com o objetivo de eliminar possíveis compostos ácidos remanescentes de sua fabricação. Do semeio até 10 dias, as espumas foram umedecidas com água da cisterna. Após 10 dias do semeio (DAS), as mudas apresentaram um par de folhas, as mesmas foram transferidas para o berçário onde iniciou-se a aplicação da solução nutritiva $S_{1}$, de modo que 33,33; 66,66 e $100 \%$ da concentração nutricional sugerida por Furlani (1999) foram aplicadas no $1^{\circ}, 7^{\circ}$ e $14^{\circ}$ dia, respectivamente. As mudas foram mantidas no berçário por 24 dias após a germinação e, após este período, foram transferidas para o perfil hidropônico definitivo. 
Research, Society and Development, v. 10, n. 14, e515101420437, 2021

(CC BY 4.0) | ISSN 2525-3409 | DOI: http://dx.doi.org/10.33448/rsd-v10i14.20437

Em função dos tratamentos as cultivares da alface foram avaliadas aos 22 dias após o transplantio para o perfil hidropônico definitivo quanto aos seguintes parâmetros:

Número de folhas por planta (NFP): consistiu na contagem do número de folhas da produção comercial partindo-se das folhas basais até a última folha aberta, Produção total (PT): consistiu da produção de massa fresca da parte aérea (caule e folhas) sendo determinada com auxílio de uma balança semi analítica, Produção comercial (PC): consistiu da produção de massa fresca da parte aérea (caule e folhas) desprezando-se as folhas amarelecidas, secas e/ou atacadas por pragas e doenças, sendo determinada com auxílio de uma balança semi analítica, Massa fresca das folhas (MFF): após determinação da produção comercial determinou-se a produção de massa fresca das folhas, com auxílio de uma balança semi analítica.

Os resultados obtidos foram submetidos ao teste de homogeneidade (Cochran e Bartlett), e ao teste de normalidade (Shapiro-Wilk). Os parâmetros de crescimento e produção foram submetidos à análise da variância pelo teste $\mathrm{F}$ a 1 e $5 \%$ de probabilidade. Quando verificado efeito significativo na análise da variância, as médias obtidas nas subparcelas (cultivares) foram comparadas pelo teste de Tukey até 5\% de probabilidade e entre as parcelas (soluções) realizou-se a análise de regressão. Para Massa Fresca do Caule (MFC) e Massa Fresca da Folha (MFF), os dados foram transformados em $1 / \sqrt{ } \mathbf{x}$ respectivamente. O Software estatístico utilizado neste trabalho foi o SISVAR (Ferreira, 2014).

\section{Resultados e Discussão}

Verifica-se na Tabela 4, as concentrações das soluções nutritivas aplicadas no cultivo da alface crespa em sistema hidropônico que influenciaram significativamente a nível de $1 \%$ de probabilidade $(\mathrm{p}<0,01)$ nas variáveis número de folha por planta (NFP) e produção total (PT) e a $5 \%(0,01 \leq \mathrm{p}<0,05)$ as variáveis produção comercial (PC) e massa fresca da folha (MFF).

Tabela 4 - Análise de variância do Número de Folha por Planta (NFP), Diâmetro Caulinar (DC), Produção Total (PT), Produção Comercial (PC), Massa Fresca da Folha (MFF), Massa Seca da Folha (MSF) e Massa seca do caule (MSC) no final do experimento do cultivo hidropônico das cultivares da alface (Elba, Cristina e Veneranda) submetida aos diferentes tratamentos

FV

GL Quadro Médio (QM)

\begin{tabular}{ccccccccc}
\hline & & NFP & DC & PT & PC & MFF & MSF $^{1}$ & MSC $^{2}$ \\
SOL & 6 & $18,22^{* *}$ & $14,50^{\text {ns }}$ & $4756,31^{* *}$ & $3062,74^{*}$ & $3062,74^{*}$ & $0.46^{\text {ns }}$ & $0,093^{\text {ns }}$ \\
BLO & 2 & $13,98^{\text {ns }}$ & $3,36^{\text {ns }}$ & $4323,21^{* *}$ & $3056,19^{*}$ & $3056,19^{*}$ & $1,85^{\text {ns }}$ & $0,30^{* *}$ \\
erro 1 & 11 & 3,64 & 7,05 & 577,17 & 651,35 & 651,35 & 0.52 & 0,03 \\
CULT & 2 & $65,25^{* *}$ & $17,64^{\text {ns }}$ & $7935,77^{*}$ & $5972,07^{* *}$ & $5972,07^{* *}$ & $7.12^{* *}$ & $0,58^{* *}$ \\
CULT*SOL & 12 & $14,08^{\text {ns }}$ & $3,96^{\text {ns }}$ & $1002,00^{\text {ns }}$ & $957,18^{\text {ns }}$ & $957,18^{\text {ns }}$ & $0.47^{\text {ns }}$ & $0,02^{\text {ns }}$ \\
erro 2 & 92 & 9,46 & 7,82 & 1738,06 & 1016,62 & 1016,62 & 0.35 & 0,025 \\
CV 1 & & 12,18 & 13,74 & 12,73 & 16,83 & 16,83 & 26.29 & 18,38 \\
CV 2 & & 19,62 & 14,47 & 22,09 & 21,03 & 21,03 & 21.61 & 15,95 \\
Média geral & & 15,67 & 19,33 & 188,73 & 151,62 & 151,62 & 2.73 & 1,00 \\
\hline
\end{tabular}

1 e 2 Dados transformados em $1 \sqrt{ } \mathrm{x}$ e $\operatorname{lnx}$, respectivamente. GL - grau de liberdade; ns não significativo; ${ }^{* *}$ significativo a nível de $1 \%$ de probabilidade $(\mathrm{p}<0,01){ }^{*}$ significativo a nível de $5 \%$ de probabilidade $(0,01 \leq \mathrm{p}<0,05)$ pelo teste $\mathrm{F}$; $\mathrm{CV}=\mathrm{coeficiente}$ de variância; $\mathrm{Q}=$ Quadrática; $\mathrm{L}=$ Regressão linear. Fonte: Autores. 
Research, Society and Development, v. 10, n. 14, e515101420437, 2021

(CC BY 4.0) | ISSN 2525-3409 | DOI: http://dx.doi.org/10.33448/rsd-v10i14.20437

Quanto ao efeito isolado das cultivares, o número de folha por planta (NFP), produção comercial (PC), massa fresca da folha (MFF), massa seca de folhas (MSF) e massa seca do caule (MSC) foram influenciadas a nível de $1 \%$ de probabilidade $(\mathrm{p}<0,01)$, enquanto que a produção total $(\mathrm{PT})$ foi afetada a $5 \%$ de probabilidade $(0,01 \leq \mathrm{p}<0,05)$ (Tabela 4).

Ao analisar o efeito da interação entre soluções e cultivares, observou-se que não houve influencia em nenhuma das variáveis analisadas (Tabela 4).

O aumento nos níveis de condutividade elétrica das soluções nutritivas promoveu uma diminuição linear nas médias observadas para número de folha por planta (NFP), (Figura 4A), produção total (PT) (Figura 4C), produção comercial (PC) (Figura 4E) e na massa seca de folhas (MSF) (Figura 4G) as médias foram as seguintes: 0,9636; 18,816 (g); 15,485 (g) e 15,487 (g) por cada incremento unitário da condutividade elétrica $\left(\mathrm{dS} \mathrm{m}{ }^{-1}\right)$, respectivamente. Estes resultados corroboram com os encontrados por Xavier et al. (2019) em sua pesquisa com água salina de poço e com diferentes cultivares da alface crespa em sistema hidropônico. Silva et al. (2020) acharam em sua pesquisa trabalhando com alface lisa em ambiente protegido com

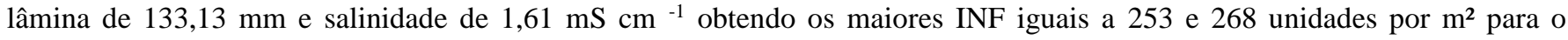
ambiente de campo e protegido, respectivamente esses resultados 
Research, Society and Development, v. 10, n. 14, e515101420437, 2021

(CC BY 4.0) | ISSN 2525-3409 | DOI: http://dx.doi.org/10.33448/rsd-v10i14.20437

Figura 4 - Número de folha por planta (A e B), produção total (C e D), produção comercial (E e F), e massa fresca de folhas $(\mathrm{G}$ e $\mathrm{H})$, da alface em função do efeito isolado dos diferentes níveis de salinidade e das cultivares da alface crespa Elba, Cristina e Veneranda. Barras verticais representam o erro padrão. $\mathrm{S}_{1}=100 \%$ da solução de Furlani $\left(\mathrm{CE} 1,9 \mathrm{dS} \mathrm{m}^{-1}\right)$ e $\mathrm{S}_{2} ; \mathrm{S}_{3} ; \mathrm{S}_{4}$; $\mathrm{S}_{5} ; \mathrm{S}_{6}$ e $\mathrm{S}_{7}$ adicionadas com cloreto de sódio $(\mathrm{NaCl})$ de modo a apresentarem as seguintes condutividades elétricas: 2,4; 2,9; 3,$4 ; 3,9 ; 4,4$ e $4,9 \mathrm{dS} \mathrm{m}^{-1}$, respectivamente.
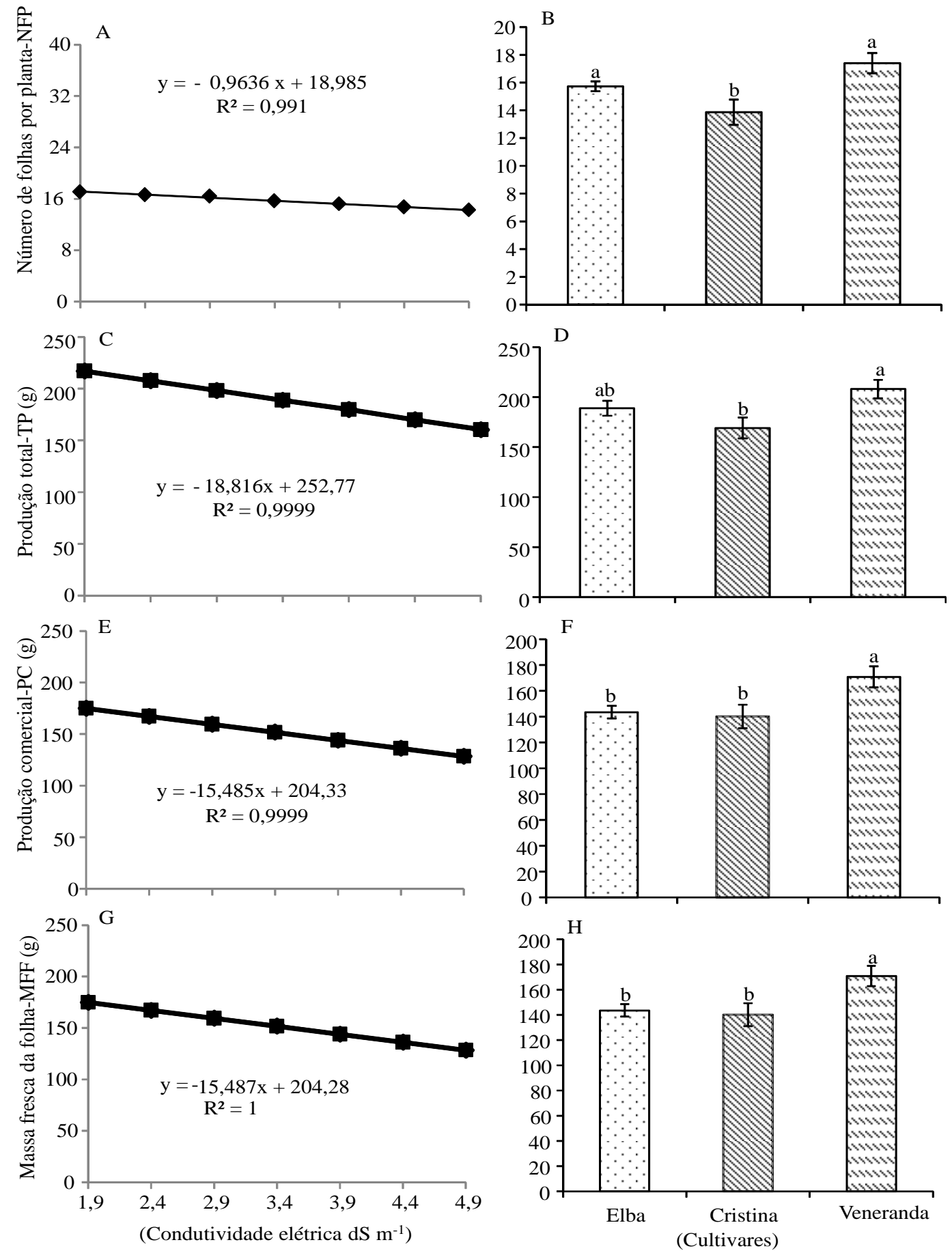

Fonte: Autores.

Entre as variáveis analisadas, o número de folha por planta (NFP), (Figura 4A), foi a menos prejudicada pelo aumento da salinidade, cuja redução foi de $16,85 \%$, comparando a sua média obtida entre o menor $\left(1,9 \mathrm{dS} \mathrm{m}^{-1}\right)$ e o maior $\left(4,9 \mathrm{dS} \mathrm{m}^{-1}\right)$ 
Research, Society and Development, v. 10, n. 14, e515101420437, 2021

(CC BY 4.0) | ISSN 2525-3409 | DOI: http://dx.doi.org/10.33448/rsd-v10i14.20437

nível de salinidade. Para a produção total (PT), (Figura 4C), produção comercial (PC) (Figura 4E), e massa fresca de folhas (MSF) (Figura 4G) a redução foi de 26,01; 26,56 e 26,57\%, respectivamente. O decréscimo no número de folha por planta (NFP), encontrado neste trabalho pode ser justificado pelos os níveis de condutividade elétrica acima do recomendado para a cultura da alface e pelas elevadas temperaturas registradas no ambiente de cultivo durante a condução do experimento. O menor desenvolvimento das plantas no sistema NFT, pode ser atribuído aos intervalos nos períodos de irrigação, as plantas podem ter passado por estresse osmótico e/ou hídrico, o que por sua vez, comprometeu o desenvolvimento das plantas (Rodríguez-Ortega et al., 2019).

Dias et al. (2011) em seu trabalho verificou uma redução no número de folhas de 4,28\% por incremento unitário, a partir da salinidade limiar de 4,28 dS m${ }^{-1}$ na cultivar Verônica. Embora o número de folhas seja uma característica da alface, temperaturas elevadas podem estimular precocemente a floração da planta. Filgueira (2008) afirma que a temperatura ideal para a cultura da alface está compreendida entre 15 e $25^{\circ} \mathrm{C}$. Dependendo da cultivar, temperaturas elevadas e dias longos podem ocasionar o pendoamento da alface. Após a indução do florescimento a planta emite o pendão floral, o que a torna imprópria para a comercialização devido gosto amargo que as folhas desenvolvem, em função do acúmulo rápido de látex Magalhães et al. (2010). Resultados encontrados por Fonseca, Schuck e Silva (2015), trabalhando com as cultivares Pira roxa, Vitália e Gloriosa, submetidas a CE de $1,8 \mathrm{dS} \mathrm{m} \mathrm{m}^{-1}$ sob cultivo hidropônico em Dourados-MS, constataram que não houve diferença significativa com relação ao número de folhas das cultivares Pira Roxa e Vitália. Vários autores reportam os efeitos da salinidade sobre o crescimento e desenvolvimento da alface (Moraes et al., 2014), mas não fazem referência ao efeito dos sais sobre a emissão de folhas, apenas reportam à redução de fitomassa da parte aérea, levando a crer que tenha havido também redução do número de folhas com o incremento da salinidade da solução nutritiva.

Quanto ao efeito isolado de cultivares, verifica-se na Figura 1B, que os maiores valores para o Número de folha por planta (NFP) foram obtidos nas cultivares Elba e Veneranda cujas médias foram de 15,73 e 17,40, respectivamente. A cultivar Cristina apresentou o menor Número de folha por planta (NFP) com valor de 13,88. Assim como verificado por Cazuza Neto et al. (2014b), utilizaram águas salina no preparo da solução nutritiva, o aumento dos níveis das águas salina acarretou um decréscimo na produção do coentro hidropônico, as plantas irrigadas com água de $7,73 \mathrm{dS} \mathrm{m}^{-1}$, apresentara sintomas de queima das bordas nas folhas mais velhas.

Observa-se na (Figura 4D) que o maior valor para a Produção total (PT) foi obtido para a cultivar Veneranda cuja média 208,06 g. A cultivar Cristina apresentou o menor a Produção total (PT) com média de 169,18 g. Os resultados obtidos nesta pesquisa para (PT) foram superiores aos obtidos por Xavier et al. (2019) que trabalharam em condições semelhantes ao desta pesquisa.

Verifica-se na (Figura 4F) que o maior valor para a Produção comercial (PC) foi obtido para a cultivar Veneranda cuja média 171,00 g. As cultivares Elba e Cristina não diferindo as médias entre si, apresentaram as seguintes médias de 143,61 e 140,25 g. Esses resultados são superiores dos obtidos por Xavier et al. (2019) que trabalharam em condições semelhante ao desta pesquisas com a cultivar Thaís utilizando soluções nutritivas preparadas com água residuária domestica otimizada e água de poço salina otimizada, cuja as médias foram de 129,54 e 116,20 g.

Observa-se na (Figura 4H) que o maior valor para massa fresca da folha foi obtido para a cultivar Veneranda cuja média 171,00 g. As cultivares Elba e Cristina não diferindo as médias entre si, apresentaram as seguintes médias de 143,61 e 140,25 g. Alves et al. (2011) estudaram a cultivar Verônica em condições similares ao desta pesquisa e encontram uma média de 339,55 g de massa de matéria fresca da parte aérea após 24 DAT, esse valor é superior ao encontrado ao desta pesquisa. Fernandes et al. (2018) trabalharam em condições semelhante ao desta pesquisas e encontraram para a matéria fresca da alface Americana valor na ordem de 136,5 g planta ${ }^{-1}$. Soares et al. (2015) estudaram o comportamento da alface americana (cv. Tainá) em condição similar ao desta pesquisa com níveis crescentes de estresse salino muito $(0,2$ - testemunha, 1,2; 2,2; 3,2; 
Research, Society and Development, v. 10, n. 14, e515101420437, 2021

(CC BY 4.0) | ISSN 2525-3409 | DOI: http://dx.doi.org/10.33448/rsd-v10i14.20437

4,2 e 5,2 $\mathrm{dS} \mathrm{m}^{-1}$ ) e em sistema hidropônico tipo NFT, perceberam que a massa fresca da parte aérea sofreram reduções $15,22 \%$ por cada incremento unitário da condutividade elétrica.

Observa-se na (Figura 5A) que o maior valor para massa seca da folha (MSF) foi obtido para a cultivar Veneranda cuja média 3,17 g. Analisando na (Figura 5B) verifica-se que o maior valor para a massa seca do caule (MSC) foi encontrado na cultivar Veneranda cuja média 1,11g. Soares et al. (2020), encontrou resultados que demonstram o efeito do aumento da salinidade na massa fresca da folha (MFF) da couve-flor como também refletiu sobre a massa seca da folha (MSF). Além disso, a menor massa seca obtida na solução mais concentrada no sistema NFT deve-se ao efeito osmótico provocado pela elevada condutividade elétrica da solução nutritiva. Paulus et al. (2011) Verificou as reduções lineares das massas seca das folhas e do caule da cultivar Pira Roxa foram superiores $7 \%$ e $10 \%$ em relação à Verônica, sendo o efeito da salinidade da água mais acentuado nas variáveis de crescimento da cultivar Pira Roxa.

Figura 5- Massa seca da folha (A) e Massa seca do caule (B) em função do efeito isolado das cultivares da alface crespa.
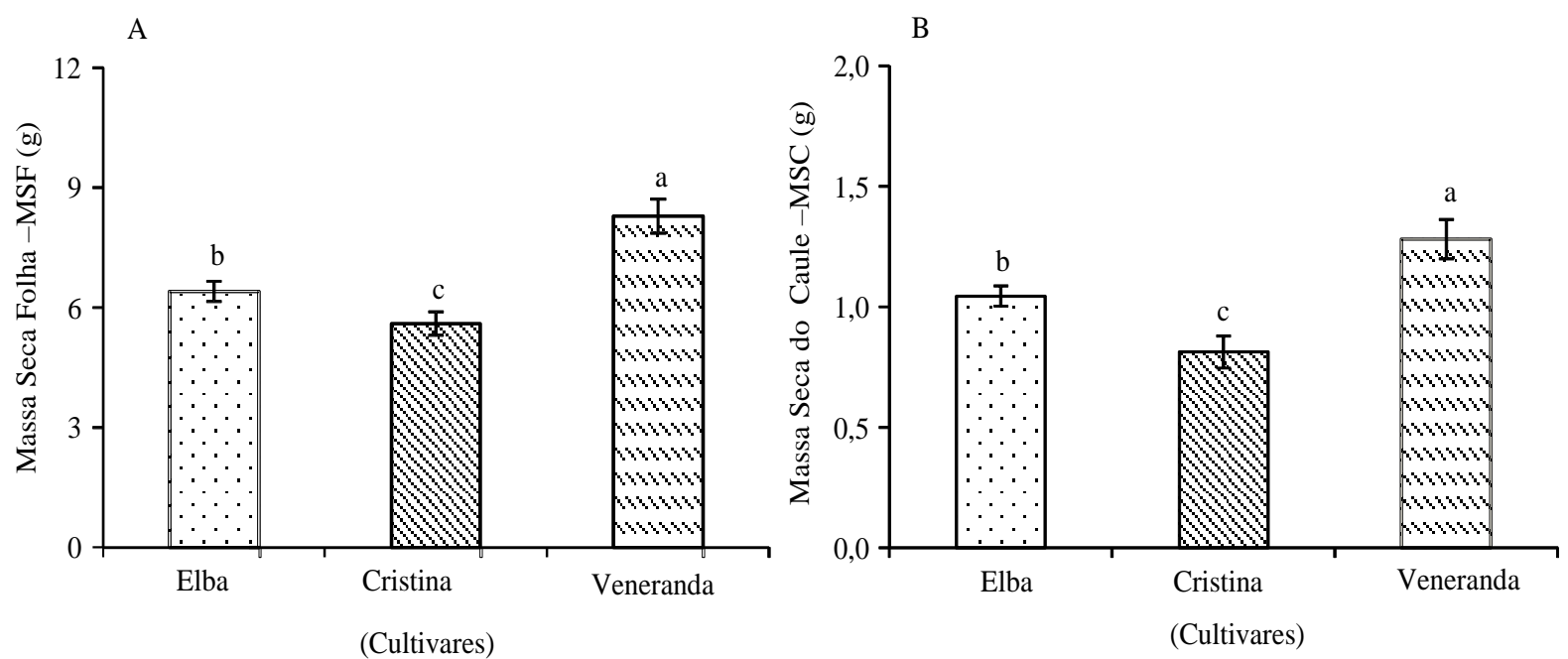

Fonte: Autores.

\section{Conclusão}

A solução nutritiva de Furlani $\left(\mathrm{S}_{1}\right)$ com condutividade elétrica de $1,9 \mathrm{dS} \mathrm{m} \mathrm{m}^{-1}$ promoveu os melhores resultados independentemente da variável estudada, com destaque maior para a variável produção comercial (PC).

$\mathrm{O}$ aumento da condutividade elétrica na solução de Furlani com a adição de $\mathrm{NaCl}$ reduziu significativamente o rendimento da alface crespa.

A cultivar Veneranda se destacou entre as demais, apresentando os maiores valores para as variáveis, número de folhas por planta (NFP) produção comercial (PC), massa fresca da folha (MSF), massa seca da folha (MSF) e massa seca do caule (MSF).

\section{Agradecimentos}

A Coordenação de Aperfeiçoamento de Pessoal de Nível Superior pelo apoio financeiro para realização da pesquisa.

Ao Centro de Ciências Agrárias e Ambientais-CCAA da Universidade Estadual da Paraíba-UEPB, Campus II, Lagoa Seca-PB por conceder a área para instalação do experimento. 


\section{Referências}

Alves, M. S., T. M; Luana T. Silva., Fernandes, J. P., Oliveira, M. L. A. \& Paz, V. P. S. (2011). Estratégias de uso de água salobra na produção de alface em hidroponia NFT. Revista Brasileira de Engenharia Agrícola e Ambiental. 15(1), 491-8. http://dx.doi.org/10.1590/S1415-43662011000500009.

Ayers, R. S. \& Westcot, D. W. (1999). A qualidade de água na agricultura. 2ed. Universidade Federal da Paraíba- UFPB, FAO,. p.153. Campina GrandeParaíba.

Brasil, Ministério da Agricultura (1971). Levantamento exploratório-reconhecimento de solos do Estado da Paraíba. Equipe de Pedologia e Fertilidade do Solo. Divisão de agrologia - SUDENE. Boletim Técnico, p. 670. Rio de Janeiro-RJ.

Cazuza Neto, A., Soares, T.M., Bione, M.A., Freitas, F.T.O., Melo, D.M., Silva Filho, J.A. (2014b). Efeito da salinidade no consumo hídrico do molho de coentro produzido em sistema hidropônico NFT. In: Brazilian Symposium on Salinity, 2, e Brazilian Meeting on Irrigation Engineering. Fortaleza. Anais.. Fortaleza: INOVAGRI/INCT-EI/INCTSal. 3685-3693 p.

Cova, A. M. W., Freitas, F. T. O., Viana, P. C., Rafael, M. R. S., Azevedo Neto, A. D. \& Soares, T.M. (2017). Content of inorganic solutes in lettuce grown with brackish water in different hydroponic systems. Revista Brasileira de Engenharia Agrícola e Ambiental. 21: 150-155. https://doi.org/10.1590/18071929/agriambi.v21n3p150-155.

Pascale, S.; Orsini, F. \& Pardossi, A. (2013). Irrigation water quality for greenhouse horticulture. In Good Agricultural Practices for Greenhouse Vegetable Crops; FAO Plant Production and Protection Paper 217; Food and Agriculture Organization of the United Nations: Rome, Italy, 169-204 p.

Dias, N. S., Jales, A. G. O., Sousa Neto, O. N., Gonzaga, M. I. S., Queiroz, I. S. R. \& Porto, M. A. F. (2011). Uso de rejeito da dessalinização na solução nutritiva da alface, cultivada em fibra de coco. Revista Ceres. 58,(1) 632-7. https://doi.org/10.1590/S0034-737X2011000500014.

Dias, N. S., Sousa Neto, O. N., Cosme, C. R., Jales, A. O., Rebouças, J. R. L. \& Oliveira, A. M. (2011). Resposta de cultivares de alface à salinidade da solução nutritiva com rejeito salino em hidroponia. Revista Brasileira de Engenharia Agrícola e Ambiental. 15(10) 991-995. https://doi.org/10.1590/S141543662011001000001.

Fernandes, J. M. P., Fernandes, A. L. M., Dias, N. S., Cosme, C. R., Nascimento, L. V. \& Queiroz, I. S. R. (2018). Salinidade da solução nutritiva na produção de alface americana em sistema hidropônico NFT. Revista Brasileira de Agricultura Irrigada. 12(3):2570-2578. DOI:10.7127/rbai.v12n300697.

Ferreira, D. F. (2014). Estatística Básica. Editora Ufla, 2ed. p.156. Ampliada e Revisada. Lavras.

Filgueira, F. A. R. (2008). Novo manual de olericultura: agrotecnologia moderna na produção e Comercialização de Hortaliças. (3a ed.). Viçosa: UFV. 421 p.

Fonseca, P. R. B., Schuck, M. B. \& Silva, J. A. N. (2015). Diferentes tipos de alface sob duas condutividades na hidroponia. Revista Eletronica da Falculdede de Ciências Exatas e da Terra. 5: 9-17.

Furlani, P.R., Silveira, L.C.P., Bolonhezi, D. \& Faquin, V. (1995). Cultivo de alface pela técnica de hidroponia - NFT. Campinas: IAC, Documentos, 55. p.18. Campinas, SP.

Gondim, A. R. O., Flores, M. E. P., Martinez, H. E. P., Fontes, P. C. R. \& Pereira, P. R. G. (2010). Condutividade elétrica na produção e nutrição de alface em sistema de cultivo hidropônico NFT. Bioscience Journal. 26(1), 894-04. http://dx.doi.org/10.18535/ijsrm.

Kim, H., Jeong, H., Jeon, J. \& Bae, S. (2016). Effects of Irrigation with Saline Water on Crop Growth and Yield in Greenhouse Cultivation. Water. 8 (4), 127; https://doi.org/10.3390/w8040127.

López, U. P, Apodaca, J. M., Petite, A. M. \& Rueda, A. M. (2014). Responses of nutrient dynamics in barley seedlings to the interaction of salinity and carbon dioxide enrichment. Environmental and Experimental Botany, Oxford, 99: 86-99. doi: 10.1016/j.envexpbot.2013.11.004.

Magalhães, A. G., Menezes, D., Resende, L. V. \& Bezerra Neto, E. (2010). Desempenho de cultivares de alface em cultivo hidropônico sob dois níveis de condutividade elétrica. Revista Horticultura Brasileira. 28(3) 316-320. https://doi.org/10.1590/S0102-05362010000300013.

Monteiro Filho, A. F., Azevedo, M. R. Q. A., Azevedo, C. A. V., Fernandes J. D., Silva, C. R. da \&. Silva, Y. dos S. (2017). Growth of hydroponic lettuce with optimized mineral and organomineral nutrient solutions. Revista Brasileira Engenharia Agrícola Ambiental. 21(1), 191-6. http://dx.doi.org/10.1590/1807-1929.

Moraes, D. P., Fernandes, A. L. M., Dias, N. S., Cosme, C. R. \& Sousa Neto, O. N. (2014). Rejeito salino e solução nutritiva em alface cultivada em sistema hidropônico. Magistra. 26: 357-364.

Oliveira, L. L. P., Farias, W. C., Linhares, P. S. F., Melo, M. R. S., Cavalcante, J. J. \& Dombronski, J. L. D. (2014). Análise de diferentes dosagens de solução nutritiva no cultivo de mudas de alface americana (Lactuca sativa L.). Revista Agropecuária Científica no Semiárido. 10(1) 14-7. http://dx.doi.org/10.30969/acsa.v10i2.503.

Paulus, D., Dourado Neto, D. \& Paulus, E. (2012). Análise sensorial, teores de nitrato e de nutrientes de alface cultivada em hidroponia sob águas salinas. Horticultura Brasileira. 30 (1) 18-25. https://doi.org/10.1590/S0102-05362012000100004.

Paulus, D., Dourado Neto, D., Frizzone, J. A. \& Soares, T. M. (2011). Produção e indicadores fisiológicos de alface sob hidroponia com água salina. Revista Horticultura Brasileira. 28 (1) 29-3. doi:10.1590/S0102-05362010000100006.

Rodriguez-Ortega, W.M.; Martínez, V.; Nieves, M.; Simón, I.; Lidón, V.; Zapata, J. C. F.; Nicolas, J. J. M.; Zapata, J. M. C. \& Sánchez, F. G. (2019). Agricultural and Physiological Responses of Tomato Plants Grown in Diferent Soilless Culture Systems with Saline Water under Greenhouse Conditions. Scientific Reports, 9.6733. doi:10.1038/s41598-019-42805-7 
Research, Society and Development, v. 10, n. 14, e515101420437, 2021 (CC BY 4.0) | ISSN 2525-3409 | DOI: http://dx.doi.org/10.33448/rsd-v10i14.20437

Sarmento, J. D. A., Morais P. L. D., Almeida, M. B., Sousa Neto, O. N. \& Dias, N. S. (2014). Qualidade e Conservação da Alface Cultivada Com Rejeito Da dessalinização. Revista Caatinga. 27, 90-7. http://dx.doi.org/10.13140/2.1.3532.3849.

Santos, R. S. S., Dias, N. S., Duarte, S. N. \& Lima, C. J. G. S. (2012). Uso de águas salobras na produção de rúcula cultivada em substrato de fibra de coco. Revista Caatinga. 25, 113-118. http://dx.doi.org/10.1590/1983-21252018v31n424rc.

Silva, C. B.; Santos, M. A. L.; Santos, D. P.; Santos, C. G. Valdevan Rosendo dos Santos, V. R. \& Sá, M. B. (2020). Produtividade da alface cultivada em campo e ambiente protegido em resposta às lâminas de irrigação e níveis salinos. Research, Society and Development, 9 (10) doi: http://dx.doi.org/10.33448/rsd

Silva, M. G., Soares, T. M., Oliveira, I. S., Santos, J. C. S., Pinho, J. S. \& Freitas, F. T. O. (2015). Produção de coentro em hidroponia NFT com o uso de águas salobras para reposição do consumo evapotranspirado. Revista Brasileira de Agricultura Irrigada. 9, 246-58. http://dx.doi.org/10.7127/rbai.v9n400319.

Silva, A. O., Silva, D. J. R., Soares, T. M., Silva, E. F. F., Santos, A. N. \& Rolim, M. M. (2011). Produção de rúcula em sistema hidropônico NFT utilizando água salina do Semiárido-PE e rejeito de dessalinizador. Revista Brasileira de Ciências Agrárias. 6, 147-55. doi:10.5039/agraria.v6i1a929.

Soares, R. H.; Silva, Ê. F. de F.; Silva, G. F.; Cruz, A. F. da S.; Santos Júnior, J. A, \& Rolim, M. R. (2020). Salinity and flow rates of nutrient solution on cauliflower biometrics in NFT hydroponic system. Revista Brasileira de Engenharia Agrícola e Ambiental. 24 (4) $258-265$.

Soares, H. R.; Silva, E. F. F.; Silva, G. F.; Lira, R. M.; Bezerra, R. R.(2016). Mineral nutrition of crisphead lettuce grown in a hydroponic system with brackish water. Revista Caatinga, Mossoró, 29 (3) 656-664. doi:10.1590/1983-21252016v29n316rc

Soares, H. R., Silva, Ê. F. F., Silva, G. F., Pedrosa, E. M. R., Rolim, M. M., Santos, A. N. (2015). Lettuce growth and water consumption in NFT hydroponic system using brackish water. Revista Brasileira de Engenharia Agrícola e Ambiental. 19 (7) 636-642. https://doi.org/10.1590/18071929/agriambi.v19n7p636-642.

Souza Neta, M. L., Oliveira, F. A., Silva, R. T., Souza, A. A. T., Oliveira, M. K. T. \& MEDEIROS, J. F. (2013). Efeitos da salinidade sobre o desenvolvimento de rúcula cultivada em diferentes substratos hidropônicos. Revista Agro@mbiente. 7 (2), 154-161. http://dx.doi.org/10.18227/19828470ragro.v7i2.947.

Taiz, L.; Zeiger, E.; Moller, I. M. Murphy, A. (2017). Fisiologia e desenvolvimento vegetal. (6 ${ }^{\text {a }}$ ed.) Artmed, p.858 Porto Alegre.

Xavier, J. F., Azevedo, C. A.V., Azevedo, M. R. Q. A., Fernandes J. D., Monteiro Filho, A. F. \& Lima, V. L. A. (2019). Application of wastewater for production of lettuce (Lactuca sativa) in hydroponic system. Australian Journal of Crop Science - AJCS. 13(10):1586-1593 doi: 10.21475/ajcs.19.13.10.p1752. 